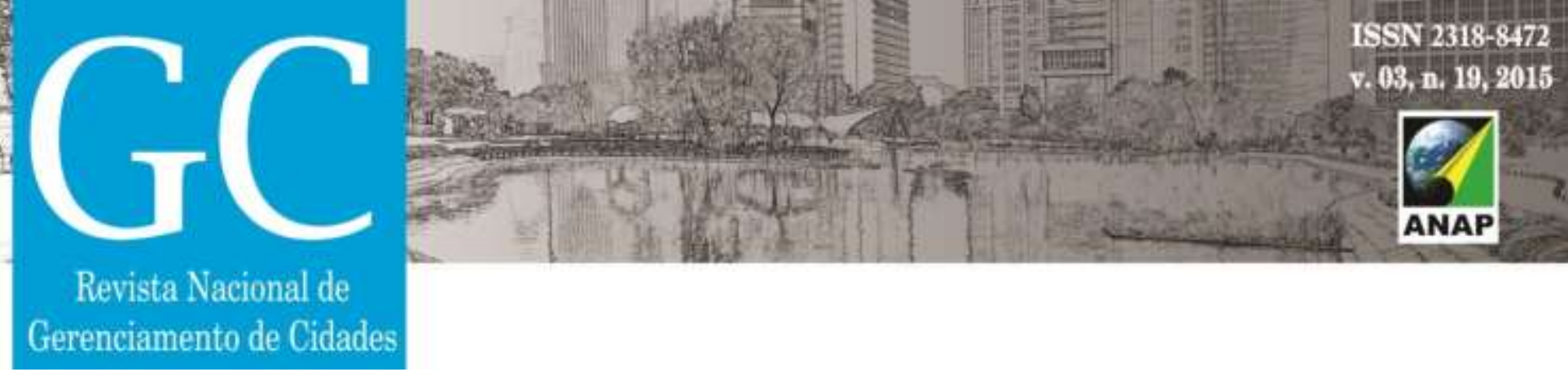

\title{
ANÁLISE DA SEGURANÇA DE PEDESTRES E CICLISTAS EM RODOVIAS URBANAS
}

\author{
Luzenira Alves Brasileiro ${ }^{1}$
}

Leticia Camila Comar ${ }^{2}$

\begin{abstract}
RESUMO
A localização da rodovia em um espaço urbano potencializa os impactos, uma vez que coloca a população em contato com todos os riscos que a rodovia apresenta. Além disto, a rodovia amplia as distâncias a serem percorridas pelos pedestres, majorando suas rotas, diminuindo os contatos com a vizinhança, e reduzindo ou suprimindo atividades cotidianas. Uma rodovia em área urbana pode se constituir em uma barreira para a cidade. Portanto, é necessário se ter o conhecimento sobre as características do tráfego da via, da localização dos elementos de travessia, das características de uso do solo da região, das características da população urbana e residente no entorno da via. O objetivo deste trabalho é analisar a segurança de pedestres e ciclistas em rodovias urbanas. Um estudo de caso foi realizado para a cidade de llha Solteira - SP. O método constituiu-se na definição de fatores de segurança propostos pela literatura. Os resultados mostraram que existem deficiências físicas e operacionais que afetam a segurança dos pedestres e ciclistas no caso que foi estudado. Pode-se concluir que as deficiências existentes geram grande número de acidentes nas três rodovias analisadas, envolvendo caminhões, automóveis, motocicletas, bicicletas e pedestres. Os acidentes ocorridos provocam danos maiores nos segmentos menos favorecidos, que são os pedestres e os ciclistas.
\end{abstract}

PALAVRAS-CHAVE: Ciclista. Pedestre. Rodovia.

\section{ANALYSIS OF PEDESTRIANS AND CYCLISTS SAFETY IN URBAN ROADS}

\begin{abstract}
The highway location in an urban space enhances the impact as it puts people in touch with all the risks that the road shows. In addition, the highway extends the distances to be traveled by pedestrians, subsequently adding their routes, reducing contacts with the neighborhood, and reducing or eliminating daily activities. A highway in urban areas may constitute a barrier to the city. Therefore, it

\footnotetext{
${ }_{1}^{1}$ Doutora em Engenharia de Transportes, UNESP - Docente. luzenira@dec.feis.unesp.br.

2 Graduanda em Engenharia Civil, UNESP - Discente. leticiacomar@yahoo.com.br
} 


\section{Revista Nacional de}

Gerenciamento de Cidades

mundo se dá por acidentes de trânsito, e desta fração, 30\% corresponde o envolvimento de pedestres e ciclistas.

No Brasil, a situação não é diferente. Segundo ARTESP (apud RIBEIRO, 2012), em 2010 ocorreram 565 acidentes que resultaram em 189 mortos nas rodovias concessionadas do Estado de São Paulo. O atropelamento é o tipo de acidente que provoca mais vítimas fatais. No Brasil, os acidentes em áreas urbanas geram, aproximadamente, custos de $\mathrm{R} \$ 5,3$ bilhões (IPEA e DENATRAN, 2006).

Muitas vezes uma cadeia de eventos ocorre durante um acidente, este tipo de ocorrência é caracterizado como seqüência. Assim, um acidente envolvendo um pedestre ou ciclista pode não ser a causa principal do evento, mas uma saída de pista pode provocar um atropelamento. Também pode ocorrer o contrário, um atropelando gerando uma saída de pista.

O propósito de estudar acidentes envolvendo pedestres e ciclistas em rodovias é encontrar soluções para diminuir os conflitos entre estes segmentos e os veículos. Para tanto, deve-se considerar os aspectos das rodovias em áreas urbanas e seus impactos na percepção dos pedestres e ciclistas.

A análise dos problemas de segurança viária não se pode restringir apenas à simples consideração da soma total e da severidade dos acidentes de trânsito acontecidos em determinada via ou região (TRB, 2004).

Em geral, a segurança viária abrange um conjunto de condições e fatores interligados que propiciam a circulação e interação dos diferentes elementos do sistema de tráfego na rede viária, sob níveis aceitáveis de risco e forma suficientemente segura.

O objetivo do estudo é analisar a segurança de trânsito oferecida aos pedestres e ciclistas nos projetos viários, no contexto particular da cidade de llha Solteira - SP, analisando medidas objetivas relacionadas com o risco de acidentes.

\section{RODOVIAS EM ÁREAS URBANAS}


A fim de diminuir os acidentes com pedestres e/ou ciclistas em rodovias, é necessário levar em conta elementos sobre as rodovias em áreas urbanas e seus impactos na percepção dos pedestres.

Segundo Silva Júnior (apud RIBEIRO, 2012), o crescimento populacional somado à especulação imobiliária da terra urbana e às facilidades relacionadas à aquisição de veículos motorizados fez com que a área urbanizada de diversos municípios fosse incorporando áreas antes isoladas pelas barreiras representadas por cursos d'água, ferrovias e rodovias.

Dessa forma, o que antes era considerado motor para o crescimento populacional e desenvolvimento econômico local, a rodovia passa a ser quase um empecilho aos deslocamentos internos urbanos. Ou seja, a rodovia trouxe à tona a realidade da convivência de acidentes de trânsito nos trechos de áreas urbanas.

$\mathrm{Na}$ maioria das vezes, os acidentes com pedestres e/ou ciclistas em rodovias se caracterizam como atropelamentos, uma vez que estas vias não trazem segurança para pedestres, ciclistas, e também para os motoristas.

A rodovia amplia as distâncias a serem percorridas pelos pedestres, e também pelos ciclistas, majorando suas rotas, reduzindo ou suprimindo atividades cotidianas.

Uma rodovia em área urbana, na maioria dos casos, se constitui em uma barreira para a cidade. Além disso, geralmente, não existem elementos de rodovia adequados para auxiliar a travessia dos pedestres e o cruzamento dos ciclistas em rodovias urbanas.

Os usuários da rodovia desejam realizar suas viagens com fluidez no tráfego, os habitantes das comunidades desejam facilidade de acessos para as atividades urbanas e ambos desejam a segurança e conforto em seus trajetos (FREIRE, 2003).

\section{FLUXO DE PEDESTRES}




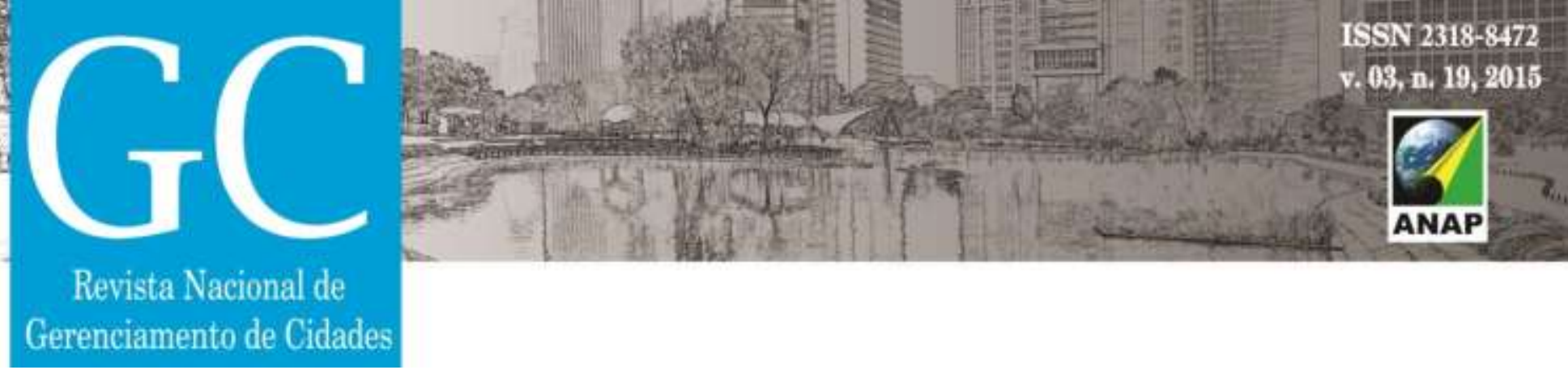

\section{FLUXO DE CICLISTAS}

As facilidades cicloviárias permitem o deslocamento dos ciclistas em trajetos compartilhados com o tráfego geral ou em trajetórias paralelas ao alinhamento das vias que atendem ao tráfego em geral. As principais facilidades cicloviárias são as seguintes:

Acostamento e Acostamentos Compartilhados:

No caso das rodovias, os acostamentos são o espaço destinado à circulação dos ciclistas, além da parada ou estacionamento de veículos em emergências. $\mathrm{Na}$ ausência de calçadas, os acostamentos são compartilhados com os pedestres.

Via Compartilhada:

Segundo AASHTO (1999), as bicicletas utilizam a via em todo lugar onde não são proibidas. Então, existe a necessidade de promover práticas de projeto de segurança para ciclistas em todas as vias. AASHTO (1999) subdivide as vias compartilhadas em vias compartilhadas e vias compartilhadas sinalizadas.

Ciclofaixa:

As ciclofaixas são dispositivos unidirecionais, com bicicletas trafegando no mesmo sentido dos veículos, e devem ser colocadas do lado direito da via, pois ciclofaixas do lado esquerdo não são comuns e são inesperadas para os motoristas.

Ciclovia:

A ciclovia é o dispositivo que funciona totalmente segregado do tráfego motorizado e apresenta maior segurança e conforto para os ciclistas.

Caminhos e Calçadas Compartilhadas: 


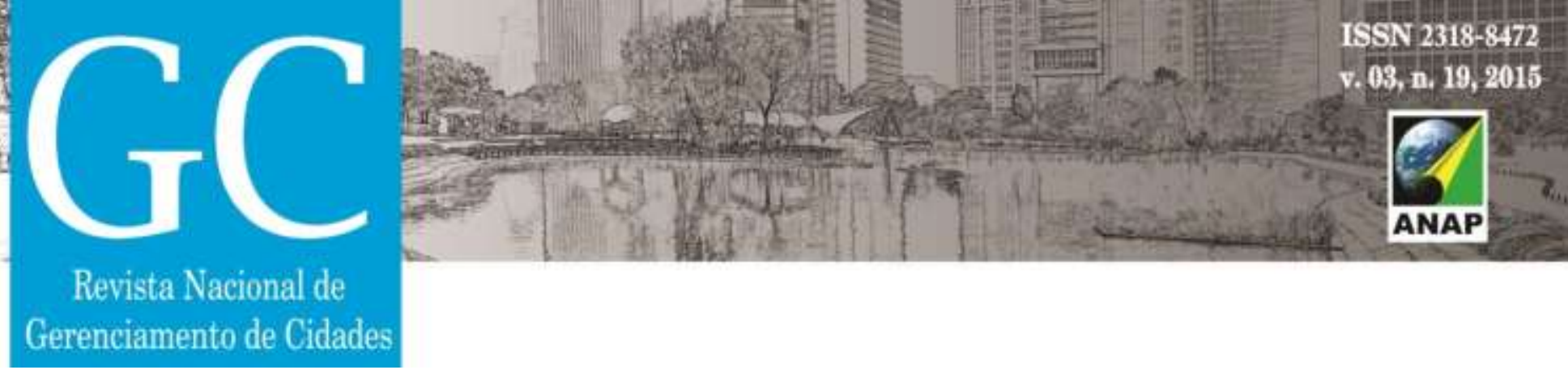

Estes também consistem em um dispositivo segregado do tráfego de veículos, porém o uso pode ser compartilhado com outros usuários.

\section{MATERIAIS E MÉTODOS}

Para suprir a dificuldade de obtenção direta e rápida de acidentes e conflitos, o conceito de oportunidade de manobra e de conflito é proposto para obter dados analíticos de segurança. Esta abordagem permite o desenvolvimento de métodos para fazer a estimativa de oportunidades de manobra e de conflito, o que toma este parâmetro uma medida potencialmente adequada para determinar o nível de segurança de um determinado local ou fazer projeções sobre a efetividade de projetos de segurança.

\section{ESTUDO DO CASO}

O estudo de caso para Ilha Solteira - SP foi desenvolvido para a realização deste trabalho porque é uma área urbana considerada como uma cidade estratégica devido a sua localização geográfica.

A cidade esta localizada na divisa de dois Estados - São Paulo e Mato Grosso do Sul, margeada por três principais rodovias - Rodovia SP 310, Rodovia Geralda Maria da Conceição e Rodovia SP 595.

Uma vez que essas rodovias estão inseridas no espaço urbano, se faz a extrema necessidade de analisar o nível de segurança que oferecem, principalmente, aos usuários não motorizados, que são os pedestres e os ciclistas.

\section{ANÁLISE DA SEGURANÇA DE PEDESTRES E CICLISTAS EM RODOVIAS URBANAS}




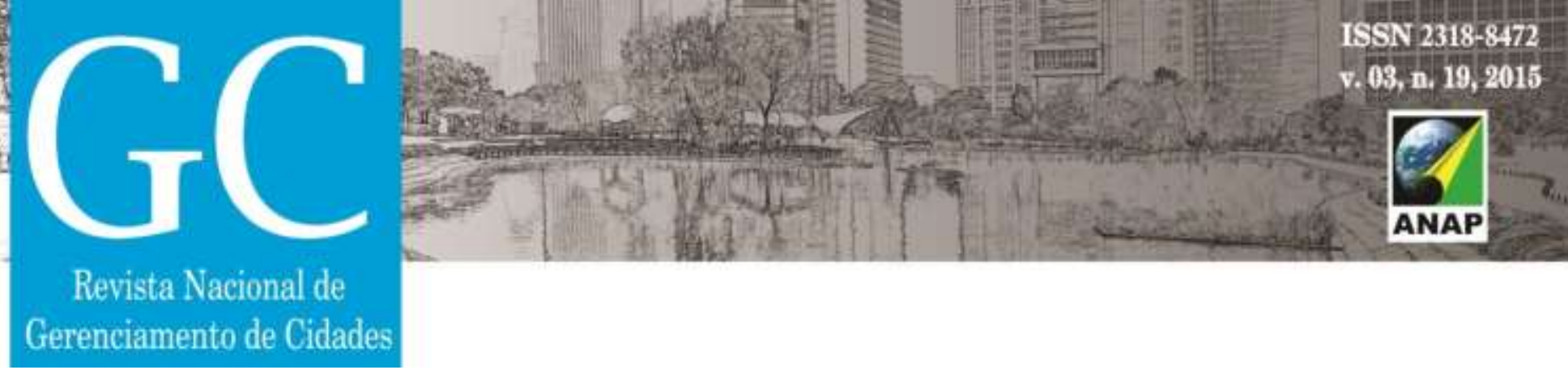

A análise da segurança de pedestres e ciclistas em rodovias urbanas deve ser realizada em relação à existência de elementos que proporcionem a acessibilidade e a mobilidade.

\section{Elementos que proporcionam a acessibilidade}

Os elementos que proporcionam a acessibilidade dos pedestres e ciclistas são relacionados a diversos fatores da urbanização e do planejamento de transportes, tais como: localização de acessos, retornos, locais de entradas e saídas.

\section{Elementos que proporcionam a mobilidade}

Os elementos que proporcionam a mobilidade dos pedestres e ciclistas referem- se às facilidades que permitem o deslocamento dos pedestres e ciclistas em trajetos compartilhados com o tráfego geral ou em trajetórias paralelas ao alinhamento das vias que atendem ao tráfego em geral.

Estes elementos também consistem nos padrões técnicos adequados para a determinação da velocidade dos veículos automotores na via e da implantação da devida sinalização.

\section{CONCLUSÕES}

A análise da segurança de pedestres e ciclistas que trafegam nas três rodovias que circundam a cidade de Ilha Solteira - SP permite concluir que existem deficiências físicas e operacionais.

As principais deficiências físicas observadas consistem em: ausência de acostamento da rodovia na parte urbana e a ausência de ciclovia ou calçadas, o que faz com que tenha uma competição entre pedestres, ciclistas e motoristas de veículos leves e pesados pela mesma faixa de rolagem da pista, em ambos os sentidos analisados. 
As principais deficiências operacionais consistem na ausência de política para definição das prioridades de uso das rodovias pelos modos de transporte e na falta de controle do limite de velocidade.

Essas deficiências geram grande número de acidentes nas três rodovias analisadas, envolvendo caminhões, automóveis, motocicletas, bicicletas e pedestres. Os acidentes ocorridos provocam danos maiores nos segmentos menos favorecidos, que são os pedestres e os ciclistas.

\section{REFERÊNCIAS BIBLIOGRÁFICAS}

AASHTO - American AssociationofStateHighwayandTransportationOfficials. Guide for theplanning, design andoperationofpedestrianfacilities. 2004.

AASHTO - American AssociationofStateHighwayandTransportationOfficials. Guide for developmentofbicyclefacilities. 2004.

BURDEN, Dan. Building Communities with Transportation. Distinguished Lectureship Presentation. Transportation Research Board - TRB, Washington, D. C. 2001.

DNIT -Departamento Nacional de Infraestrutura de Transporte. Manual de travessias urbanas. 2010.

FREIRE, L. H. C. V.; 2003. Análise de Tratamentos Adotados em Travessias Urbanas Rodovias Arteriais que Atravessam Pequenas e Médias Cidades no RS. Dissertação de Mestrado Profissionalizante, Capítulos 4 e 6.

IPEA - Instituto de PesquisaEconômicaAplicada e DENATRAN - Departamento Nacional de Trânsito.ImpactosSociais e Econômicos do Acidentes de TrânsitonasRodoviasBrasileiras. RelatórioExecutivo. Brasília. 2006.

RIBEIRO, Andrea Laurindvicius. Método de Análise de ProjetosViários para Melhoria da Segurança de Pedestres e CiclistasemRodoviasConcessionadasPaulistas. Dissertação (Mestrado), Departamento de Engenharia de Transportes, Escola Politécnica, Universidade deSão Paulo - USP. 2012. 333 p.

TRB - TransportationResearchBoard. DevelopmentoftheHighwaySafety Manual. NCHRP Web Document 62 (Project 17-18[4]). Contractor's Final Report. NationalCooperativeHighwayResearchProgram. Whashington, Estados Unidos da America. 2004. 